\title{
A crise ambiental e a ecologização do capital em uma leitura marxista: valor, renda e crise
}

\section{Julio Cesar Pereira Monerat ${ }^{1}$}

Resumo: O artigo desenvolve o conceito de ecologização do capital a partir do referencial teórico marxiano, definindo-a como forma capitalista de enfrentamento da crise ambiental que é causada pelo próprio movimento do capital. Inicia-se relacionando a crise ambiental e a dinâmica necessariamente expansiva do capital referenciada na categoria valor. Essa dinâmica expansiva tem sua complexidade destacada, na sequência, pelo estudo da renda fundiária, quando se verifica o caráter desigual e combinado da expansão capitalista sobre o ambiente. $\mathrm{O}$ artigo realiza, em seguida, um paralelo analítico entre a crise ambiental e a crise do capital relacionada ao valor, identificando o caráter tendencial das crises no capitalismo e seu fundamento na eliminação proporcional do trabalho vivo em relação ao trabalho objetivado. A análise dos elementos da crise ambiental - relacionados ao estudo prévio da renda fundiária e à dinâmica expansiva do capital sobre a natureza - permite identificar que, na crise ambiental, atuam contratendências e, mais do que isso - o que revela uma contribuição analítica importante para o debate ambiental no marxismo -, que a ecologização do capital tem a potencialidade de atuar ela mesma como uma tendência contra-arrestante à crise capitalista ao converter obstáculos ambientais em fronteiras para a expansão do capital.

Palavras-chave: Crise ambiental. Crise do capital. Ecologização.

Abstract: The article develops the concept of greening capital from the Marxian theoretical framework, defining it as a capitalist way of confronting the environmental crisis that is caused by the movement

\footnotetext{
${ }^{1}$ Doutorado em Serviço Social (UERJ), mestrado em Geografia (UFJF), graduação em História (FIC). Professor de História no IF Sudeste MG - Campus Muriaé. Coordenador da RETEP (Rede Tecnológica de Extensçao Popular).
} 
of capital itself. It begins by relating the environmental crisis and the necessarily expansive dynamics of capital referenced in the value category. This expansive dynamic has its complexity highlighted, in the sequence, by the study of land income, when the unequal and combined character of capitalist expansion on the environment is verified. The article then makes an analytical parallel between the environmental crisis and the crisis of capital related to value, identifying the tendential character of crises in capitalism and its foundation in the proportional elimination of living work in relation to the objectified work. The analysis of the elements of the environmental crisis - related to the previous study of land income and the expansive dynamics of capital over nature - allows us to identify that, in the environmental crisis, countertrends act and, more than that - which reveals an important analytical contribution to the environmental debate in Marxism - that the greening of capital has the potential to act itself as a counter-trend to the capitalist crisis by converting environmental obstacles into frontiers for the expansion of capital.

Keywords: Environmental crisis. Crisis of capital. Greening.

\section{Introdução}

Iniciemos conceituando a ecologização do capital. Para isso, mais que relacionar a crise ambiental do tempo presente com o modo de produção capitalista - o que não se configura como uma novidade analítica - é preciso caracterizá-la como uma crise ambiental do capital. Com essa caracterização - na qual a preposição "do" estabelece o sentido específico - estamos considerando que a crise ambiental e sua inserção na agenda capitalista a partir do momento em que os problemas ambientais, decorrentes da própria lógica expansiva do capital, passam o obstaculizar o movimento continuado e expansivo do valor. Daí que sinteticamente temos a conceituação de crise ambiental do capital enquanto acúmulo de barreiras à valorização capitalista. Essa conceituação de crise ambiental como crise relacionada aos obstáculos à valorização também não significa desconhecer que esteja

\begin{tabular}{l|l}
\hline 2 & A crise ambiental e a ecologização do capital...
\end{tabular} 
efetivamente em andamento uma crise ambiental para o conjunto da humanidade. Entretanto, nosso foco analítico está voltado para as formas desenvolvidas pelo capital para o enfrentamento da ambiental que obstaculiza seu movimento de produção de valor. E é o conjunto dessas medidas que abarcamos sob a denominação de formas de ecologização do capital.

De um modo bastante sintético, consideramos como ecologização do capital, portanto, um conjunto de medidas que abarcam a internalização efetiva dos problemas ambientais na agenda do capital. Nesse conjunto amplo não estão elencadas as medidas com alcance restrito ao marketing verde e que não efetivam minimamente qualquer prática ambientalmente sustentável, naquilo que se caracteriza como greenwashing. Sendo assim, notadamente, estão abarcadas as medidas implementadas pelo capital que efetivamente internalizam os custos ambientais - que, em grande medida, eram anteriormente externalizados -, o que pode acontecer por modalidades diversas: eficiência energética, reciclarem, bioeconomia, financeirização dos problemas ambientais (bolsas verdes, pagamentos por serviços ambientais), agricultura de precisão, enfim, uma ampla gama de esverdeamento do capital.

Por suposto há também formas de ecologização que não são diretamente efetivadas pelo capital, mas sim por setores não diretamente capitalistas - ainda que inescapavelmente presos à lógica mercantil -, tais como a produção agroecológica praticada por camponeses, indígenas, quilombolas e grupos que são com modos de vida específicos - que não vem ao caso aprofundar mo presente artigo. Enfatizemos que o escopo da presente abordagem não objetiva listar e muito menos analisar as formas específicas de ecologização do capital, mas sim apreendê-la em sua dinâmica global de forma articulada à dinâmica expansiva do capital em relação à natureza e, consequentemente à crise ambiental que decorre dessa mencionada dinâmica expansiva. 
Reforçando nosso foco na crítica à ecologização do capital, é preciso salientar que tal ecologização capitalista pode até, em determinadas circunstâncias, acarretar efeitos benéficos em relação à mencionada crise ambiental em geral, mas certamente não é este seu objetivo determinante. Mais exatamente - destaquemos - o objetivo da ecologização do capital é superar os obstáculos ambientais à valorização e, nesse sentido, efeitos sobre a sustentabilidade em geral são meros resultados acessórios. E é também nesse sentido que identificamos como elemento fundante da ecologização do capital o aprofundamento dos processos de mercadorização da natureza - que adquirem uma escala inaudita no contexto da crise ambiental.

A primeira determinação da ecologização do capital discutida relaciona-a ao caráter necessariamente expansivo do capital, mais exatamente à sua caracterização como valor que se valoriza (MARX, 2013) e que já carrega consigo outra determinação: a contradição entre, de um lado, o caráter ilimitado do valor - representado na mercadoria-dinheiro - e, de outro, a limitação do ambiente natural dentro de arranjos sociotécnicos historicamente estabelecidos. Sendo assim, a primeira sessão o artigo apresenta a caracterização da lógica necessariamente expansiva do valor e verifica seu desdobramento na relação entre capital e natureza. Enquanto a apresentação da lógica expansiva é referenciada no Livro I de O Capital (MARX, 2013) a relação capital-natureza referencia-se nas considerações marxianas sobre a renda fundiária (MARX, 2017), sendo que a conjugação dessas referências reforça que a dinâmica expansiva do capital é carreada de contradições e desenvolve-se de modo desigual e combinado.

Na segunda sessão, o artigo estabelece um paralelismo entre a crise ambiental do capital à crise do capital propriamente dita - aquela diretamente referente ao valor e, consequentemente à contradição elementar do movimento do capital que contraditoriamente reduz progressivamente o trabalho vivo produtor de valor em relação ao trabalho já objetivado. A análise salienta o caráter tendencial das crises capitalistas e realiza um paralelo com a crise ambiental.

\begin{tabular}{l|l}
\hline 4 & A crise ambiental e a ecologização do capital...
\end{tabular} 
Avançando criticamente - e aqui se encontra a relevância teórica do presente artigo - o artigo conclui afirmando que a ecologização do capital, mais do que a forma capitalista de enfrentar a crise ambiental do capital, tem a potencialidade de atuar como contratendência à crise do capital propriamente dita. Isso porque o capital, em seu movimento de superação das crises que obstaculizam sua expansão, busca converter seus limites - limites internos e limites ambientais - em barreiras a serem ultrapassadas no sentido de renovar sua dinâmica expansiva. Por certo que nesse referido movimento de superação dos limites determinados por suas contradições com a força de trabalho e com a natureza, respectivamente -, as contradições não são simplesmente eliminadas, mas sim superadas no sentido de serem simultaneamente suprimidas e recolocadas em patamares mais aprofundados, em uma dinâmica tendencial que, se por um lado revela-nos o caráter histórico do capitalismo, não nos permite datar e prever a forma de sua crise final.

É esse o itinerário que percorremos a seguir.

\section{Contradições, tendências e limites na relação entre capital e natureza: valor e renda}

O capitalismo é um modo de produção tautológico no sentido de que o objetivo da produção não é a satisfação das necessidades humanas, mas sim que tais satisfações apenas servem de suporte ao objetivo último da produção: a produção de valor, cuja substância é o trabalho abstrato e cuja medida é o tempo de trabalho socialmente necessário. Em outros termos, a troca mercantil - sintetizada na fórmula M-D-M, na qual uma mercadoria $(\mathrm{M})$ com determinado valor de uso é trocada por dinheiro (D) para ser, na sequência, trocada por outra mercadoria (M) com valor de uso distinto - não passa de aparência fenomênica ${ }^{2}$ do

${ }^{2}$ Marx identifica a mercadoria como uma unidade contraditória de valor de uso e valor. Em termos marxianos: "A utilidade de uma coisa faz dela um valor de uso" (MARX, 
movimento mais profundo no qual o valor de uso é mero suporte do valor (MARX, 2013), este sim o motor do capital. Sendo, portanto, o dinheiro a representação do valor, será a fórmula D-M-D' - dinheiro que, tendo percorrido o circuito de produção e troca mercantil, retorna ampliado à sua origem - aquela que sintetizará o movimento de valorização em sua essência.

Por se tratar de uma relação que tem por parâmetro o elemento quantitativo dessa forma de riqueza abstrata que é o valor, a produção necessita ser crescente, já que não haveria sentido em intercambiar quantidades iguais dessa riqueza que não se distingue qualitativamente da contraparte intercambiada. Em outros termos, seria uma total absurdidade caso o movimento do capital tivesse o objetivo de "realizar, percorrendo seu ciclo inteiro, a troca de um mesmo valor em dinheiro pelo mesmo valor em dinheiro" (MARX, 2013, p. 224). Salientemos, portanto, que, a produção mercantil, enquanto produção de valor que tão somente se distingue de outro valor quantitativamente, só faz sentido se objetivar a expansão do valor inicialmente colocado em movimento. Enfim,

2013, p. 113), cuja efetivação ocorre no próprio consumo da mercadoria. Marx (2013, p. 113) destaca que "Os valores de uso formam o conteúdo material da riqueza qualquer que seja a forma social desta". Mas, antes de tratar propriamente do valor, Marx (2013, p. 113) discute o valor de troca, identificando que ele "aparece inicialmente como a relação quantitativa, a proporção na qual valores de uso de um tipo são trocados por valores de uso de outro tipo, uma relação que se altera constantemente no tempo e no espaço". Ou seja, o valor de troca aparece na comensurabilidade das mercadorias. E justamente por revelar-se apenas na comensurabilidade é que Marx identifica o caráter relativo (que se altera, que depende de uma relação com outra mercadoria) do valor de troca, concluindo que ele é a aparência de algo mais profundo: o valor: "O elemento comum, que se apresenta na relação de troca ou valor de troca das mercadorias, é, portanto, seu valor" (MARX, 2013, p. 115). Certamente que uma discussão aprofundada sobre o valor escapa aos objetivos deste artigo, cabendo-nos tão somente indicar, na trilha marxiana, que o valor tem por substância o trabalho abstrato, isto é, "o trabalho que constitui a substância dos valores é trabalho humano igual, dispêndio da mesma força de trabalho humana" (MARX, 2013, p. 115). Por sua vez, o valor tem por medida o tempo de trabalho socialmente necessário, tal qual esclarece Marx (2013, p. 116): a "quantidade de trabalho socialmente necessário ou o tempo de trabalho socialmente necessário para a produção de um valor de uso que determina a grandeza de seu valor". O artigo apresenta uma breve discussão dessas categorias, mas tão somente com o objetivo de identificar a processualidade que se propõe a analisar.

\begin{tabular}{l|l}
\hline 6 & A crise ambiental e a ecologização do capital...
\end{tabular} 
produção de valor, portanto, produção capitalista, é necessariamente produção determinada pelo movimento quantitativamente expansivo que advém da condição elementar de ser produção de mercadorias.

Detalhando um pouco mais a lógica expansiva do capital, que decorre do caráter mercantil da produção, a partir da categoria dinheiro, verificamos que, por ser a forma aparente da riqueza universal, o dinheiro (re)vela a determinação expansiva de forma mais acabada, de modo que: "a figura de valor da mercadoria, o dinheiro, torna-se, agora, o fim próprio da venda, e isso em virtude de uma necessidade social que deriva do próprio processo de circulação" (MARX, 2013, p. 209). Ao fim e ao cabo, considerada a partir do dinheiro, a lógica expansiva revela-se como impulso permanentemente amplificado e desmedido por mais dinheiro. O que fica mais claro nessa colocação marxiana nos Grundrisse: "o capital, como representante da forma universal da riqueza - do dinheiro -, é o impulso ilimitado e desmedido de transpor seus próprios limites. Cada limite é e tem de ser obstáculo para ele. Caso contrário, deixaria de ser capital - o dinheiro que se produz a si mesmo" (MARX, 2011, p. 261).

E acrescenta, reforçando o caráter desmedido da lógica expansiva do capital: "a circulação do dinheiro como capital é, ao contrário, um fim em si mesmo, pois a valorização do valor existe apenas no interior desse movimento sempre renovado. O movimento do capital é, por isso, desmedido" (MARX, 2013, p. 228; grifos nossos). Um movimento, entretanto, fundamentalmente contraditório posto que só é possível quando historicamente o capital encontra no mercado uma mercadoria específica cujo uso realiza a criação de um mais-valor. A contradição, como veremos adiante na análise da crise capitalista, é que o movimento necessariamente expansivo do capital acaba por reduzir tendencial e proporcionalmente o trabalho vivo - produtor de valor - em relação ao trabalho já objetivado. E, também como anotaremos adiante, esta é uma contradição inescapável ao capital, o que reforça seu caráter histórico. Mas não apenas esta contradição - à qual retornaremos caracterizará o movimento do capital, já também sua relação com a 
natureza será fundada na contradição. É essa relação que passamos a tratar na sequência.

Mais exatamente, partimos da compreensão da crise ambiental como um limite ao capital que pode ser sinteticamente definido pela contradição entre o caráter necessariamente expansivo do capital e o caráter limitado (ou o ritmo de renovação diferenciado) dos recursos naturais, o que se efetiva em determinadas condições sociotécnicas historicamente estabelecidas, porém mutáveis. Superando visões lineares e fundamentando-nos em Marx, constatamos que a natureza não se configura somente como um limite ao avanço do capital, podendo sim, em determinadas circunstâncias, ser convertida em uma vantagem ou mesmo fronteira para a expansão do capital. E que, além disso, a própria condição de limite ou vantagem não é dada pela natureza, mas por condições sociotécnicas historicamente determinadas nas quais o metabolismo socioambiental e os limites dele decorrentes modificam-se ao longo do tempo.

Um desdobramento necessário dessas observações é que aquilo que se apresenta como limite natural será um limite colocado a essa forma social por essa mesma forma social em um dado contexto histórico. No caso em foco: são limites ambientais que decorrem da dinâmica capitalista e que, contraditoriamente, acabam por obstaculizá-la. Mas é também na forma social capitalista que se deve buscar compreender as soluções efetivadas para a superação daqueles obstáculos naturais - soluções essas relativas à dinâmica do valor. Nesse sentido, o estudo do capital na agricultura revela-se importante fonte para a compreensão da relação entre capital e natureza ao destacar que uma condição natural - a fertilidade do solo, no caso - tem sua condição de vantagem ou desvantagem socialmente determinada.

A fertilidade do solo não é uma condição absoluta, alterandose no decorrer das mudanças na história natural e social, mas, o mais importante, é que sua relevância para o metabolismo socioambiental é determinada pela sociabilidade capitalista. É nessa sociabilidade caracterizada pela lógica expansiva que o capital avança sobre o

\begin{tabular}{l|l}
\hline 8 & A crise ambiental e a ecologização do capital...
\end{tabular} 
campo e, consequentemente, faz com que condições naturais passem a ser determinadas pela dinâmica da valorização. As peculiaridades da atuação do capital na agricultura são-nos reveladas pelo estudo marxiano da renda fundiária sumarizados a seguir.

É no Livro III de O Capital que Marx (2017) concluirá que a renda fundiária capitalista pressupõe o desenvolvimento da produção capitalista não apenas no campo, mas a produção generalizada de mercadorias, isto é, que a produção de valor seja o fundamento da produção social e, portanto, que haja produção de mais-valor inclusive no trabalho agrícola. Por seu turno, o monopólio da terra - fruto de dada relação social - franqueia a seu proprietário o recebimento de uma renda que certamente não brota naturalmente do solo, mas resulta da força produtiva do trabalho em determinadas condições de diferenciação das condições naturais (MARX, 2017). Como monopólio de uma condição natural diferenciada "essa renda, evidentemente, é sempre diferencial", uma renda que "deriva da diferença entre o preço de produção individual do capital individual, que tem à disposição a força natural monopolizada, e o preço de produção geral do capital investido nessa esfera de produção” (MARX, 2017, p. 709).

Conforme ressalta Lenz (1992, p. 52): “o que acontece, segundo Marx, é que a medição da renda da terra é feita em função do solo em que foi gerada, o que obscurece a sua verdadeira fonte, a sua forma de mais-valor". Ou seja, é a produção de valor que tem prioridade em relação à propriedade da terra, ainda que seja justamente a propriedade fundiária que permite a captura de uma renda pelo proprietário. É essa prioridade da produção de valor que, agora considerada na relação capital-natureza apreendida a partir do estudo da renda fundiária, determina a incorporação crescente da natureza na dinâmica da valorização.

Essa necessidade expansiva do capital com relação à natureza tem um exemplo marcante no avanço do capital em direção a solos ainda que de menor fertilidade. Isso porque, no contexto de uma maior demanda por produtos agrícolas, haveria a elevação de seus 
respectivos preços, tornando vantajoso o investimento nos solos com fertilidades inferiores. Marx (2017, p. 732) observa que "é claro que o avanço em direção a um solo pior jamais ocorre por livre escolha; [ele] pode apenas ser consequência - pressupondo-se o modo de produção capitalista - do aumento dos preços e, em qualquer modo de produção, só pode decorrer da necessidade". A incorporação de solos de fertilidade inferior, por seu turno, contribui para a elevação da renda nos solos mais férteis, pois são justamente aqueles menos férteis agora incorporados que passarão a ser os solos reguladores dos preços de produção. O caráter expansivo fica patente, portanto, quando se verifica que a expansão acontece pela incorporação de novos espaços (os piores solos) $e$ pelo incremento da renda dos melhores solos.

Certamente que tal dinâmica expansiva pode vir acompanhada de processos ambientalmente destrutivos. Marx exemplifica essa situação ao se referir à fertilidade natural do solo do estado de Nova York, que tornava aquelas terras especialmente adequadas ao plantio de trigo, "mas um cultivo predatório tornou estéreis essas terras férteis, e foi então que o solo de Michigan apareceu como o mais fértil" (MARX, 2017, p. 732). O exemplo confirma que a condição natural é socialmente determinada, posto que solos anteriormente preteridos Michigan - foram incorporados, num processo que, por sua vez, tem consequências econômicas e ambientais.

A condição da natureza como vantagem ou barreira enquanto determinação do contexto sociotécnico fica clara quando se analisa, por exemplo, a produção do petróleo. Há locais em que a exploração é preterida em favor de outros nos quais os custos de produção são mais baixos. Tais locais são, então, mantidos inexplorados até que ocorra uma mudança no referido contexto sociotécnico. Uma mudança elementar seria o esgotamento das reservas outrora mais vantajosas - o que equivaleria ao avanço para áreas inexploradas, tal qual no exemplo marxiano de avanço do cultivo em direção a Michigan. Mas há outras mudanças de contexto que são também importantes. Por exemplo, os custos de se produzir naquelas áreas preteridas podem vir

$\overline{10} \quad$ A crise ambiental e a ecologização do capital... 
a ser reduzido em decorrência de aprimoramentos técnicos, ou mesmo pode acontecer que a demanda e a consequente elevação do preço do petróleo justifique as expansão para aquelas áreas, mesmo que as áreas anteriormente exploradas não tenham se esgotado ou que mudanças técnicas tivessem barateado a produção. Nesse caso, um obstáculo inicial converteu-se numa vantagem com o passar do tempo, revelando a historicidade das condições ambientais (FOLADORI, 2001).

A relação da condição natural em de vantagem ou barreira tendo por referência o contexto sociotécnico, entretanto, não potencializa o capital com uma plasticidade adaptativa sem limites. Isso porque, com o esgotamento da fertilidade natural - e também da quantidade de terra disponível - o capital precisa assumir um papel mais relevante na produção agrícola, o que faz com que Marx analise um segundo tipo de renda diferencial, caracterizada não apenas como monopólio de uma vantagem natural, mas como a renda originada da aplicação sucessiva no mesmo solo de diferentes capitais e apresentando produtividades também diferentes. Trata-se, portanto, de uma fertilidade artificialmente aumentada, que converte o capital "no elemento decisivo do cultivo" (MARX, 2017, p. 739).

Em outros termos, "se ao longo da evolução for preciso fornecer um produto maior do que se pode produzir com ajuda dessa força natural, quer dizer, se esse produto adicional tiver de ser fabricado sem a ajuda dessa força natural ou com assistência de intervenção humana, de trabalho humano, um elemento adicional entrará no capital" (MARX, 2017, p. 806). Nesse caso, haverá a necessidade de "um desembolso de capital relativamente maior para obter o mesmo produto. Mantendo-se inalteradas as demais circunstâncias, ocorrerá um encarecimento da produção" (MARX, 2017, pp. 805-6). Em síntese: uma vantagem natural inicial pode, posteriormente, ser insuficiente, demandando mais trabalho e capital, ou seja, um limite natural que, dadas as condições sociais determinadas pela forma mercadoria, requer esforços para ser superado. 
E mais uma vez reforçando a importância do contexto sociotécnico para a determinação das condições naturais diferenciadas como vantagem ou barreira, anotamos que a possibilidade efetiva de realizar inversões de capital que alterem as condições naturais não é dada a todos os capitais particulares. Para alguns capitais a barreira natural se revelará um obstáculo social intransponível não em decorrência da própria natureza, mas como consequência da impossibilidade de realizarem os investimentos no aparato técnico necessário para enfrentarem os demais capitais que, por outro lado, realizarão tais inversões e garantirão sua expansão - sobre os ambientes e sobre os concorrentes arruinados, o que reforça as dinâmicas de centralização de capital. Enfim, limites naturais, porém socialmente determinados.

O estudo da renda fundiária - sobre o qual fizemos um brevíssimo esboço - demonstra-se, portanto, capaz de explicar os fundamentos do caráter expansivo do capital na agricultura bem como as formas em que essa expansão concretiza-se de modo contraditório, incorporando movimentos desiguais, ainda que combinados. Apesar desse avanço desigual e combinado do capital no campo - o que inclui a incorporação de solos com diferentes fertilidades de modo nem sempre linear - ele é fundamentalmente um avanço sobre novas áreas. Isso é, podemos identificar uma tendência de incorporação de novos solos ao longo da escala temporal e também da ampliação dos investimentos de capital na terra. Isso nos leva a concluir que, independentemente da dinâmica que assuma - dos melhores solos aos piores ou vice-versa ou ainda zigzagueando - o caráter expansivo é seu fundamento.

E essa dinâmica só é possível porque esses solos em piores condições, quando inseridos na produção, passam a desempenhar o papel de reguladores dos preços das mercadorias agrícolas. Nessa dinâmica, não apenas os piores solos poderão puncionar uma parcela do valor social na forma de renda absoluta, mas também os solos mais férteis terão ampliadas suas parcelas nesse valor social devido à elevação da renda diferencial, que terá passado a ser calculada com base no pior solo incorporado. Ou seja, a lógica espacialmente expansiva revela-se

$\overline{12}$ A crise ambiental e a ecologização do capital... 
na existência da renda fundiária (e esta, por sua vez, fundamenta-se no valor); desde que a renda seja possível, novos solos serão inseridos no circuito de produção agrícola capitalista.

\section{Crise do capital e crise ambiental: o caráter tendencial das crises}

A relação contraditória entre capital e natureza precisa ainda ser complementada com o entendimento do caráter tendencial das leis sociais, tal como Marx (2017) nos permite depreender da sua análise da lei tendencial da queda da taxa de lucro. Nosso objetivo, sendo mais precisos, é identificar o caráter tendencial da queda da taxa de lucro e, a partir daí, verificar sua capacidade de contribuir para a compreensão da crise ambiental.

Marx verifica que a queda tendencial da taxa de lucro configurase como uma tendência e, como tal, recebe a atuação de contratendências. Com isso, a formulação elementar dessa lei tendencial relaciona o aumento da composição orgânica do capital à queda da taxa de lucro, mas, ao mesmo tempo, relaciona-a aos fatores também tendenciais que obstaculizam a realização da tendência, ou seja, que "as mesmas causas que engendram a tendência à queda da taxa de lucro moderam também a efetivação dessa tendência" (MARX, 2017, p. 275). Não se perca de vista, porém, que esse movimento, "como um processo objetivo que constantemente vai em frente, mas que, ao fazê-lo, também acumula tensões, as quais apenas podem ser aliviadas quando a acumulação se inverte em desacumulação de capital" (PRADO, 2014, p. 129).

A correta compreensão da crise no quadro da lei tendencial da taxa de lucro deve ser realizada da mesma forma que se compreende o objeto - o capital - do qual ela faz parte, isto é, deve ser compreendida tendo por fundamento a contradição. Como contradição em processo, a dinâmica do capital é marcada pela colocação e superação de obstáculos decorrentes de seu próprio movimento de valorização. Recordando que superação não consiste simplesmente em eliminação, mas implica em supressão e preservação, ou seja, na recolocação das contradições em 
patamares mais aprofundados, também a compreensão da crise obriganos a superar - suprimir/preservar - a contradição entre necessidade absoluta e pura aleatoriedade que a caracteriza (GRESPAN, 2012).

A superação das visões unilaterais da crise - como determinismo ou como eventualidade - requerem ainda a consideração de um elemento temporal a respeito da relação entre crise e finitude do capitalismo, isto é, se a queda da taxa de lucro levaria a uma crise final do capitalismo. E também aqui não são cabíveis alternativas excludentes do tipo que a crise significa o necessário fim do capitalismo ou, no sentido inverso, que o modo de produção capitalista poderia superála continuadamente. Por certo que, de uma perspectiva temporal, seria um erro atribuir eternidade ao modo de produção capitalista, da mesma forma que seria temerário atribuir-lhe uma data e forma de término. Ainda mantendo um sentido temporal para a análise da crise, cabe-nos recorrer a Marx (2017, p. 288) quando afirma que "essas diversas influências se fazem sentir, ora de maneira mais justaposta no espaço, ora de maneira mais sucessiva no tempo; o conflito entre as forças antagônicas desemboca periodicamente em crises. Estas são sempre apenas violentas soluções momentâneas das contradições existentes, erupções violentas que restabelecem por um momento o equilíbrio perturbado".

Recorrendo diretamente a Marx (2017), acompanhemos sua apresentação da lei da queda tendencial da taxa de juros - ainda que a possibilidade de crise seja apresentada por ele em diferentes momentos de sua obra. Marx expõe a lei tendencial da queda da taxa de lucro comparando capitais com composições orgânicas numa escala crescente, porém, mantendo-se a mesma taxa de mais-valor e verifica, a partir daí, a ocorrência da queda gradual da taxa de lucro:

A mesma taxa de mais-valor, com um grau de exploração constante do trabalho, seria expressa assim numa taxa decrescente de lucro, porque, com seu volume material, também aumenta, ainda que não na mesma proporção, o volume de

\begin{tabular}{l|l}
\hline 14 & A crise ambiental e a ecologização do capital...
\end{tabular} 
valor do capital constante e, com isso, do capital total. Se, além disso, partirmos do pressuposto de que essa alteração gradual na composição do capital não se opera simplesmente em esferas isoladas da produção, mas, em maior ou menor grau, em todas ou pelo menos nas esferas decisivas da produção e que, portanto, essas alterações afetam a composição orgânica média do capital total existente numa determinada sociedade, chegaremos necessariamente à conclusão de que crescimento gradual do capital constante em proporção ao variável tem necessariamente como resultado uma queda gradual na taxa geral de lucro, mantendo-se constante a taxa do mais-valor, ou seja, o grau de exploração do trabalho pelo capital (MARX, 2017, pp. 249-50).

Marx relaciona a queda da taxa de lucro diretamente ao processo de produção, mais especificamente à redução proporcional do trabalho vivo produtor do mais-valor:

Como a massa total do trabalho vivo agregado aos meios de produção diminui em relação ao valor desses meios de produção, diminui também o trabalho não pago e a parcela de valor na qual ele se representa, em relação ao valor do capital total adiantado. Ou: uma alíquota sempre menor do capital total desembolsado converte-se em trabalho vivo, e esse capital total suga, assim, cada vez menos mais-trabalho em relação a sua grandeza, embora a proporção entre a parte não paga do trabalho empregado e a parte paga deste último possa crescer simultaneamente (MARX, 2017, p. 253).

Marx, contudo, não apenas identifica a queda da taxa de lucro em seu caráter tendencial, mas aponta que a lei sofre influências contraarrestantes, isto é, influências cujo objetivo é evitar que a queda da taxa de lucro efetive-se. Marx ( cf. 2017, pp. 271-7) indica as seguintes tendências contra-arrestantes, que apresentamos sinteticamente: 
aumento da exploração da força de trabalho (prolongamento e intensificação do trabalho), compressão do salário abaixo de seu valor, barateamento dos elementos do capital constante, superpopulação relativa, comércio exterior e aumento do capital acionário.

E Marx conclui que a atuação das tendências contra-arrestantes "não derrogam a lei, porém enfraquecem seus efeitos". E ele reforça: "é assim que a lei atua apenas como tendência, cujos efeitos só se manifestam claramente sob determinadas circunstâncias e no decorrer de longos períodos" (MARX, 2017, p. 277). Essas observações são importantes para que não se caia num relativismo que coloque num mesmo patamar a tendência e as contratendências. Afinal, não teria sentido identificar a lei caso as contratendências anulassem-na de maneira absoluta. Com isso Marx, sem assumir qualquer postura de previdente do futuro, denega qualquer relativismo e reforça que as crescentes dificuldades postas pelo movimento contraditório do capital revelam a historicidade desse modo de produção.

Consideramos que a crise ambiental também deva ser compreendida em seu caráter contraditório no qual atua uma tendência geral destrutiva - tendo em vista as determinações ambientalmente expansivas do valor frente aos limites naturais socialmente determinados -, mas que é contrarrestada por contratendências ambientalmente sustentáveis, isto é, as contratendências que atenuam, ao menos temporária e parcialmente, a referida dinâmica destrutiva. Com isso, estamos apontando, por um lado o movimento do capital cria obstáculos ambientais que ameaçam sua valorização e, por outro, a capacidade do capital em superar os limites colocados por sua própria lógica contraditória com a natureza, ou seja, tendência e contratendência atuantes na processualidade da crise ambiental.

Uma consideração importante é que a ecologização possui um caráter contraditório, desigual e combinado. Ou seja, o capital, ao buscar alternativas para a superação da crise ambiental o faz de maneira que contraditoriamente combina soluções ambientalmente sustentáveis com a continuidade de dinâmicas destrutivas. Dentre

\begin{tabular}{l|l}
\hline 16 & A crise ambiental e a ecologização do capital...
\end{tabular} 
as medidas de ecologização do capital podemos mencionar todo um conjunto de processos de gestão capitalista dos problemas ambientais que, como afirmado no início, passa a fazer parte da agenda ambiental do capital. Tais medidas são tomadas no espaço das empresas em sua relação com os consumidores preocupados com a sustentabilidade, seja no âmbito das organizações multilaterais e chegando mesmo a uma consciência ambiental difusa que conjuga a esperança em soluções técnicas à adoção de ações pontuais. Mas, principalmente, os problemas ambientais passam a ser internalizados à dinâmica do capital naquelas situações em que os custos ambientais configurem-se como obstáculos ao valor - cuja complexidade foi destacada no estudo da renda fundiária.

Medidas como a ecoeficiência energética e agriculturas sustentáveis, por exemplo, são combinadas ao processo de valorização em diferentes escalas e localidades: agricultura de precisão, agroecologia e uso intensivo de agrotóxicos convivem sob as determinações do valor. A novidade é que, enquanto a produção ambientalmente destrutiva já estava constituída como produção capitalista, a produção sustentável representa uma fronteira para a expansão do capital, o que se revela como tendência contra-arrestante à crise ambiental do capital.

Mas, mais do que isso - e aqui está uma contribuição importante da nossa análise -, ressaltamos que as alternativas postas pelo capital para a superação da crise ambiental - as tendências que atuam em direção à sustentabilidade - repercutem como tendências contra-arrestantes na crise do próprio capital. Enfim, ao promover a sua ecologização, o capital, coerentemente com o que temos afirmado que a sustentabilidade almejada é a sustentabilidade do próprio capital, inaugura uma nova contratendência à crise do valor - que se junta ao aumento exploração força de trabalho, ao prolongamento da jornada de trabalho e da intensificação do trabalho, ao barateamento dos elementos do capital constante, à superpopulação relativa, ao comércio exterior, essa nova contratendência é a ecologização do capital. 


\section{Apontamentos finais}

Pelas potencialidades abertas pela ecologização do capital em relação à crise do capital propriamente dita, é preciso enfatizar: da mesma forma que a crise do capital não nos permite prever de seu fim inexorável, a crise ambiental capitalista não significa a inexorabilidade do fim do capitalismo, sendo antes um dos elementos da crise do capital, ao mesmo tempo que se constitui, por meio da ecologização, como uma potencial contratendência a essa crise.

Verificando essa capacidade de superar limites, mas também de colocá-los em níveis contraditoriamente mais profundos, Marx (2017, p. 289) anota que "a produção capitalista tende constantemente a superar esses limites que lhes são imanentes, porém consegue isso apenas em virtude de meios que voltam a elevar diante dela esses mesmos limites, em escala ainda mais formidável. O verdadeiro obstáculo à produção capitalista é o próprio capital".

Ainda reconhecendo a enorme capacidade adaptativa do capital que o leva a transformar os obstáculos ambientais em formas de acumulação ao mercadorizar a natureza, não se pode esquecer que as condições ambientais permanecem como limites que impedem qualquer absolutização da capacidade adaptativa do capital. Dito de outra forma, mesmo que portador de grande capacidade de superar os obstáculos de determinadas condições naturais, o capital é incapaz de suplantar de maneira definitiva e absoluta os limites naturais que decorrem de sua própria lógica imanentemente expansiva. $\mathrm{O}$ que reforça a ideia de superação dos obstáculos até aqui desenvolvida: supressão e recolocação das contradições.

Por fim, tendo concluído que a ecologização representa uma contratendência à crise do capital - crise em geral porque relacionada aos obstáculos internos ao mais-valor -, é preciso salientar que, tal como as demais contratendências, a ecologização não derroga em definitivo o caráter imanente da crise para o metabolismo do capital. De volta às determinações expansivas do valor tratadas no 
início da exposição, temos que o aumento da produtividade implica no aumento proporcional do trabalho objetivado em detrimento do trabalho vivo, ou seja, da força de trabalho. E essa condição - o aumento da produtividade por meio da crescente superfluidade da força de trabalho, ou seja, do elemento que cria o mais-valor tornado crescentemente supérfluo - é uma contradição interna ineliminável ao movimento do capital, portanto, fundamento do caráter imanente das crises capitalistas.

Nessa direção, a análise da renda fundiária revela-nos que as condições naturais - ecologizadas, que sejam - tornam-se vantajosas não porque do solo brotem as riquezas, mas sim por tornarem mais produtivo o trabalho nelas realizado. E é justamente na mencionada relação contraditória entre capital e trabalho - trabalho vivo e trabalho objetivado - que está o fundamento último da crise que faz do capitalismo um modo de produção histórico e, portanto, finito - mesmo que promova uma permanente fuga para frente na qual a ecologização constitui-se em um recente elemento contratendencial que se junta aos demais.

\section{Referências}

FOLADORI, Guillermo. Limites do desenvolvimento sustentável. Campinas - SP: Editora da Unicamp, 2001.

GRESPAN, Jorge. O negativo do capital. São Paulo: Expressão Popular, 2012.

LENZ, Maria Heloísa. A categoria econômica renda da terra. Porto Alegre: Fundação de Economia e Estatística Siegfried Heuser, 1992.

MARX, Karl. O Capital: Crítica da economia política, Livro I O processo de produção do capital. São Paulo: Boitempo, 2013. 
MARX, Karl. O Capital: Crítica da economia política, Livro III O processo global da produção capitalista. São Paulo: Boitempo, 2017.

MARX, Karl. Grundrisse: Manuscritos econômicos de 1857-1858. Esboços da crítica da economia política. São Paulo: Boitempo, 2011.

PRADO, Eleutério. Lei de Marx: Pura lógica? Lei empírica? In: Rev. Soc. Bras. Economia Política, São Paulo, n. 37, p. 119-142, jan. 2014. Disponível em: http://www.revistasep.org.br/index.php/SEP/article/ view/48. Acesso em: 04/10/2021.

20 A crise ambiental e a ecologização do capital... 